\title{
Rede de atenção ao idoso: fatores facilitadores e barreiras para implementação
}

\section{I ${ }^{1}$ Lívia Pereira Coelho, ${ }^{2}$ Luciana Branco da Motta, ${ }^{3}$ Célia Pereira Caldas I}

Resumo: Este artigo tem por objetivos identificar e discutir os fatores que favorecem e os que dificultam a implementação de uma Rede de Atenção ao Idoso em um município com $100 \%$ de cobertura pela Estratégia Saúde da Família. Foi utilizada a metodologia qualitativa, com a realização de dez grupos focais e entrevista semiestruturada com o gestor de saúde do município. Os resultados foram contrastados com dados da estrutura do sistema de saúde local. O estudo revela que lógica atual do processo de trabalho da ESF não diferencia a assistência ao idoso à do adulto. Apesar da consolidação da atenção primária como porta de entrada e da forte atuaçấo dos agentes comunitários de saúde no município estudado, a fragmentação do sistema de saúde e a ausência de um modelo de atenção à saúde da pessoa idosa ainda são grandes limitadores da assistência a essa população. Esse contexto é agravado pela deficiência dos recursos humanos e pelo cenário de desvalorização social da velhice. Espera-se que os conhecimentos gerados possam se transformar em subsídios para a implementação de um modelo de atenção à saúde do idoso adequado à realidade local.

> Palavras-chave: saúde do idoso; atenção à saúde do idoso; atenção primária; Estratégia de Saúde da Família.

\author{
1 Programa de Pós Graduação em \\ Ciências Médicas, Faculdade de \\ Ciências Médicas, Universidade \\ do Estado do Rio de Janeiro. \\ Rio de Janeiro-RJ, Brasil \\ (liviacoelhogeriatria@gmail.com) \\ ORCID: 0000-0002-8006-0809 \\ ${ }^{2}$ Universidade Aberta da Terceira \\ Idade, Universidade do Estado do \\ Rio de Janeiro. Rio de Janeiro-RJ, \\ Brasil (lubmotta@gmail.com). \\ ORCID: 0000-0001-9959-9719 \\ ${ }^{3}$ Faculdade de Enfermagem, \\ Universidade do Estado do Rio de \\ Janeiro. Rio de Janeiro-RJ, Brasil \\ (celpcaldas@hotmail.com). \\ ORCID: 0000-0001-6903-1778
}

Recebido em: 14/08/2017 Aprovado em: 08/08/2018 Revisado em: 13/09/2018 


\section{Introdução}

Em um cenário de aumento da longevidade, espera-se um número crescente de incapacidade e da necessidade de cuidados prolongados. O declínio funcional gera aumento das necessidades, tanto para o indivíduo e família, quanto para os serviços de saúde na avaliação, tratamento, reabilitação e suporte social (VERAS, 2009).

Considerando a necessidade de mudança do paradigma do modelo de saúde vigente, emergiram no Brasil debates sobre a necessidade da implementação das Redes de Atenção à Saúde (RAS). Segundo Mendes (2011), as RASs são conjuntos de serviços de saúde, vinculados entre si por uma missão única e por uma ação cooperativa e interdependente, que permitem ofertar uma atenção contínua e integral a determinada população. Constituem-se de três elementos: a população, a estrutura operacional e o modelo de atenção à saúde (MENDES, 2010; 2011). Um grande marco para o Sistema Único de Saúde (SUS) foi a Portaria 4.279/2010 (BRASIL, 2010), que estabeleceu as diretrizes para a organização da RAS. Ela apregoa o papel central da Atenção Primária à Saúde (APS) como ponto de comunicação e ordenação do fluxo de usuários na rede, devendo ser estruturada de forma dispersa, a fim de que atinja toda a populaçáo definida. É nesse contexto que a Estratégia Saúde da Família (ESF) se destaca. Inserida no primeiro nível de atenção, a ESF assume o papel primordial na implementação das ações de saúde para essa população e na coordenação do fluxo de usuários idosos no sistema de saúde (BRASIL, 2007).

Entretanto, apesar do avanço da legislação brasileira, a prática da assistência ao idoso ainda é insatisfatória (BRASIL, 2006; MARTINS et al., 2014). Algumas características do sistema de saúde brasileiro dificultam a elaboração de um modelo mais coeso com as necessidades dessa população. A deficiência dos recursos humanos prejudica o planejamento do cuidado e o bom desempenho das ações de saúde para esse grupo etário (MOTTA; AGUIAR, 2007). Não se pode esquecer que, além das questôes específicas à população idosa, muitas dificuldades advêm de como os processos de trabalho estão desenhados. Os profissionais de saúde e gestores enfrentam desafios diários na sua prática de trabalho ao se defrontarem com um sistema de saúde desorganizado, onde os pontos de atenção se encontram isolados e sem comunicação (GIOVANELLA et al., 2009; MENDES, 2010). Quinderé, Jorge e Franco (2014) apontam ainda o excesso de burocratização do sistema de referência e contrarreferência como obstáculos para o acesso de usuários aos serviços prestados. 
Elaborar modelos para idosos a partir de doenças crônicas tem se mostrado um equívoco (VERAS, 2012). Estudiosos buscam hoje estratégias que possam atender às demandas dessa população cujo declínio funcional se apresenta como a mais relevante manifestação a ser combatida e que apresenta um perfil de múltiplas comorbidades e de alta utilização dos recursos de saúde (VERAS, 2012; MORAES, 2012). Em 2014, o documento Diretrizes para o cuidado das pessoas idosas no SUS, publicado pelo Ministério da Saúde (BRASIL, 2014), definiu como estratégia principal a assistência à população idosa do SUS a partir do Modelo de Atenção Integral. Esse documento também aborda a importância e o potencial do trabalho em rede, definindo como estratégia a integração com os diferentes pontos de atenção do SUS, visando à produção do cuidado integral à pessoa idosa, adequado as suas necessidades.

A integração de um serviço a uma RAS pressupóe que muitas vezes este, sozinho, não conseguirá resolver de forma completa as demandas dos usuários. Com vistas a definir a melhor estratégia terapêutica para solucionar as demandas desse grupo etário, discute-se a implantação de um modelo de planejamento de cuidados baseado na estratificação de risco do idoso e na avaliação multidimensional como forma de diagnóstico pela APS (MORAES, 2012; BRASIL, 2014). Nos modelos de atenção integral à pessoa idosa (BRASIL, 2014), o usuário idoso deverá sempre estar vinculado à APS e esta, por sua vez, deverá estar articulada e integrada aos outros pontos de atenção. Assim, é garantida a continuidade do cuidado, levando à redução da probabilidade de evolução para perda funcional e melhoria da qualidade da assistência. Esse modelo sustenta as redes de atenção ao idoso já desenvolvidas em alguns territórios (VERAS et al., 2014).

Utilizando a construçấo teórica de Mendes (2011) sobre as RAS, Moraes (2012) propóe a estruturação de uma Rede de Atenção ao Idoso, com forte regulação pela APS, onde há a comunicação vertical e horizontal entre o Sistema Único de Saúde e o Sistema Único de Assistência Social (SUAS), seus programas e profissionais, além de açôes intersetoriais. A partir da gestão dos sistemas de saúde e da gestão da saúde individual, discute a implantação de um modelo de planejamento de cuidados baseado na estratificação de risco, utilizando o diagnóstico multidimensional com o objetivo de definir a estratégia terapêutica e intervençôes propostas dentro dos serviços de saúde e na comunidade (MORAES, 2012).

Nesse contexto, estudos sobre a atenção ao idoso no Brasil ganham relevância onde o fortalecimento da APS surge como uma oportunidade de mudança de 
paradigma na assistência. Este artigo tem por objetivos identificar e discutir, à luz do referencial teórico de Mendes (2011) e Moraes (2012), os fatores que favorecem e os que dificultam a implementação de uma Rede de Atenção à Saúde do Idoso em um município com $100 \%$ de cobertura pela ESF. Para atingir os objetivos, foi realizado um estudo de metodologia mista que triangulou três fontes de dados sobre a assistência ao idoso no município. Espera-se que os resultados deste estudo possam se transformar em subsídios para a implementação de um modelo de atenção à saúde do idoso adequado à realidade local.

\section{Metodologia}

Este artigo apresenta dados do Projeto ISUS - Idosos no SUS, realizado pelo Grupo de Pesquisa Envelhecimento e Saúde, da Universidade do Estado do Rio de Janeiro. Esta pesquisa foi aprovada pela Comissão de Ética em Pesquisa da Universidade do Estado do Rio de Janeiro (parecer no 014.3.2010). Obteve financiamento da Fundação Carlos Chagas Filho de Amparo à Pesquisa do Estado do Rio de Janeiro - FAPERJ (Edital FAPERJ/ SESDEC/ MS/ CNPq/ N.o 18/2009) e recebeu autorização da Secretaria Municipal de Saúde de Piraí para a realização da pesquisa. Trata-se de um estudo de caso baseado na utilização de metodologia qualitativa. O município de Piraí foi escolhido por possuir 100\% de cobertura pela ESF.

O processo diagnóstico foi pautado na análise das percepçôes do gestor municipal de saúde e do processo de trabalho dos profissionais de saúde da família, combinados à avaliaçáo de dados sobre a estrutura operacional do sistema de saúde municipal. A coleta de dados foi realizada por meio de dez grupos focais, contando com 108 profissionais das dez unidades de saúde da família, no período de maio a setembro de 2012. A escolha dos sujeitos para os grupos focais foi por conveniência, sendo selecionados oito a 15 profissionais de saúde de ensino médio e superior, por grupo focal. Os grupos focais foram realizados dentro das unidades de saúde da família (USF) por um moderador e um relator, baseados em um roteiro para a discussão sobre temas pertinentes ao processo de trabalho junto aos usuários idosos. As experiências vividas nas USFs pelas equipes foram discutidas no coletivo dos profissionais de saúde a partir do olhar do fluxograma descritor. O fluxograma descritor, descrito por Merhy e Onocko (1997), representa uma ferramenta usada para a análise qualitativa do modelo de atenção. Isto permitiu a identificação de tendências e padrōes no 
processo de trabalho nas diferentes USFs, além da compreensão da percepção dos profissionais de saúde sobre ruídos existentes na assistência ao idoso e os pontos de sucesso neste acompanhamento.

A visão do gestor foi obtida por meio de uma entrevista semiestruturada, acerca da estrutura e organização do sistema de saúde do município de Piraí e os desafios encontrados na gestáo da atenção à população idosa. Todos os participantes do grupo focal e o gestor assinaram o termo de consentimento livre e esclarecido (TCLE). As informaçóes que configuraram o cenário do estudo pautaram-se por dados demográficos e da rede assistencial acessados no DATASUS, como o Cadastro Nacional de Estabelecimentos de Saúde - CNES (DATASUS, 2014a) e o Sistema de Informações da Atenção Básica - SIAB (DATASUS, 2014b). Além disso, também foram utilizadas fontes de dados documentais disponibilizados pela Secretaria de Saúde Municipal que continham informaçôes não disponíveis nas bases de dados públicas, como o Relatório de Gestão da Saúde (2009) e o Plano Municipal de Saúde, 2010-2013 (2011).

Para atingir mais precisamente os significados manifestos e latentes trazidos pelos sujeitos, as transcriçóes produzidas foram submetidas à análise de conteúdo na modalidade temática (MINAYO, 2013). A partir da análise do conteúdo das entrevistas, as categorias Atenção Primária à Saúde e Articulação da APS com outros pontos da atenção surgiram como núcleos de sentido. As informaçôes foram sistematizadas em ideias centrais dos relatos dos profissionais de saúde e do gestor de saúde nas categorias referidas, que foram organizadas como "percepçóes positivas" e "percepçóes negativas" nas opiniōes dos sujeitos. Os resultados descritos abaixo abrangem as percepçóes sobre os componentes do sistema de saúde do município para atendimento à população idosa e as ligaçôes materiais e imateriais que comunicam estes pontos a partir da atenção primária. Foram assim também abordadas as questôes relativas à integralidade e intersetorialidade no município.

\section{Cenário do estudo}

No período do estudo, o município de Piraí contava com 13 equipes de saúde da família, totalizando 197 profissionais de saúde inscritos e distribuídos entre as dez unidades de saúde da família (USF) e duas subunidades. Essas equipes eram responsáveis pelo atendimento aos pacientes conforme área de abrangência predefinida de cada USF, realizando também visitas domiciliares. De acordo 
com dados do SIAB (2014b), o município possuía cobertura de 100\% pela ESF desde 2008. Os serviços da atenção secundária e terciária e de apoio diagnóstico e terapêutico, como consultas ambulatoriais a especialistas, exames e procedimentos, eram oferecidos nos Centros de Especialidades Médicas e Odontológicas, no Hospital Municipal Flávio Leal e nos estabelecimentos acordados pelos consórcios intermunicipais, primordialmente nos municípios da Regional de Saúde do Médio Paraíba. Participaram da pesquisa 108 profissionais, sendo eles: 58 agentes comunitários de saúde, seis médicos, 11 enfermeiros ou gerentes de unidade, oito técnicos ou auxiliares de enfermagem, cinco auxiliares de consultório dentário, 11 estagiários de medicina, seis dentistas, um nutricionista e dois fisioterapeutas.

Segundo dados do DATASUS, em 2012, a população de Piraí era de 26.948 habitantes, sendo 3.358 maiores de 60 anos. A transição demográfica em estágio mais avançado pode ser demonstrada neste município pela maior porcentagem de indivíduos idosos residentes (12,5\%) quando comparada à média brasileira (10,7\%) daquele ano (DATASUS, 2014c). De acordo com dados do SIAB (2014b), entre 2002 e 2012, o número de consultas a usuários maiores de 60 anos sofreu um aumento de $126 \%$.

\section{Resultados e discussão}

As discussões de temas cotidianos na ESF revelaram não só os problemas relacionados à prática do trabalho no acompanhamento ao idoso, mas também o uso do patrimônio de conhecimento existente nas equipes de saúde da família para resolver os problemas de saúde desse grupo.

\section{Categoria Atenção Primária}

O alicerce da prática da atenção primária no município de Piraí é o agente comunitário de saúde (ACS). É ele quem sinaliza para a sua unidade a chegada de novo morador e a necessidade de inclusão de um usuário nos agendamentos das visitas domiciliares.

Aqui não tem essa de não conseguir atendimento no posto. Até porque se o idoso não consegue vir, a gente vai até ele. [...] (ACS, G2).

Entre os aspectos positivos identificados, a elevada abrangência populacional da APS no município certamente foi a mais relevante. Diferente do apontado no estudo 
realizado por Martins et al. (2014), que identificou que apenas metade dos idosos acessava a APS em Porto Alegre, o município de Piraí se destacou pelo amplo acesso dessa população à ESF. A grande capilaridade da ESF no município, atingida por meio da atuação dos ACSs e da construção de unidades de saúde da família em todos os distritos de Piraí, permitiu que $100 \%$ da população fosse cadastrada. A priorização da contratação e incentivo à formação técnica em enfermagem de profissionais que atuavam na função de ACS foi vista como sucesso pelo gestor e pelos profissionais de saúde, aumentando o vínculo da população com a equipe de saúde da família.

Os idosos acompanhados pela ESF eram atendidos no programa de hipertensão e diabetes, nos dias de atendimento de livre demanda ou em visitas domiciliares. As repercussōes do aumento da população idosa no município aparecem nas falas dos sujeitos em seis grupos focais como experiências negativas para o processo de trabalho. Não há um modelo de atenção ao idoso no município, sendo os idosos atendidos com os mesmos protocolos de acompanhamento do adulto. Os depoimentos ilustraram a ideia de que o aumento do número de idosos resulta em um tempo maior de consulta principalmente para os médicos, maior demanda para visitas domiciliares, aumento de trabalho para os profissionais e aumento da fila de espera por consulta médica. Ainda que levantadas diversas dificuldades pertinentes à assistência ao idoso nos grupos focais, não houve ênfase à necessidade de implementação de açôes específicas para a Saúde do Idoso na Atenção Primária em Piraí.

[...] $\mathrm{O}$ atendimento ao idoso demora mais. E o idoso tem prioridade no atendimento na livre demanda. Então ficam usuários não idosos com dificuldade de serem atendidos. A própria médica sugeriu um dia específico para atendimento ao idoso (Enfermeiro, G5).

Os relatos dos sujeitos dos grupos focais oscilaram entre ideias de excesso de demanda e a queixa de falta de recursos humanos, principalmente da categoria médica. Seguindo esta lógica, por um lado, trazem em suas falas que o grande número de usuários cadastrados na unidade, o atendimento a usuários não adscritos e o maior tempo de atendimento despendido ao idoso prejudicam a produçáo de consultas. Por outro, a falta de médicos dificulta a organização das USFs para realizar o acompanhamento de usuário, levando à sobrecarga dos outros profissionais. A assistência é centrada na consulta médica e o modelo, pautado na produção e não na resolução das demandas dos usuários.

Em nenhum grupo focal os saberes e práticas médicas foram contestados, tanto pelos próprios médicos, quanto pelos profissionais que com ele compartilhavam a 
rotina de trabalho. A deficiência na capacitação foi mencionada apenas pelo gestor. Os sentidos atribuídos ao acompanhamento ao idoso foram, em sua maioria, permeados pelo desconhecimento do processo do envelhecimento e suas implicaçóes às demandas de saúde dessa população. Motta e Aguiar (2007) apontam que o trabalho interprofissional no acompanhamento ao idoso, apesar de preconizado, é implementado no SUS com restriçôes, seja pela deficiente capacitação dos profissionais de saúde, seja pela dificuldade de incorporar os princípios do trabalho em equipe nas relações de trabalho.

Mas o grande problema nosso, rotatividade de médico. Cai a qualidade da assistência. É horrível! Esse médico novo, ele não entra capacitado. E como roda muito, você não tem tempo de preparar esse profissional. [...] (Gestor de saúde).

Apesar disso, é necessário considerar que, além da questão do saber, o ato de produção do cuidado ao idoso pode ser negligenciado devido à falta de recursos essenciais para o processo de trabalho ou devido às dificuldades advindas de como este processo está desenhado. Não obstante a implementação do Programa Saúde da Família com o objetivo de mudança do modelo médico-hegemônico (BRASIL, 1996), a assistência à saúde, tal como é praticada hoje, é ainda marcada por uma forte visão biologicista do processo saúde-doença, voltando-se prioritariamente para ações curativas. $\mathrm{O}$ trabalho desenvolvido pelas equipes multiprofissionais que constituem os NASFs, na orientação de casos e construção de projetos terapêuticos para idosos (BRASIL, 2014), não foi citado como atuante no município.

As ações de promoção da saúde e prevenção de doenças no município eram promovidas por atividades itinerantes organizadas pela Atenção Primária e pela Assistência Social. A característica demográfica do município de possuir muitos moradores em áreas rurais de difícil acesso, a presença de grande número de idosos portadores de incapacidade funcional e a deficiência de açóes intersetoriais, como transporte e urbanização, foram apontados como fatores que prejudicavam as açôes de saúde desenvolvidas.

Os discursos também ressaltam que a ineficiência das açôes de prevenção e promoção da saúde contribuíam para o aumento dos atendimentos de urgência nas USFs. Além da dificuldade de acesso da população idosa aos locais onde são oferecidos as açôes de promoção à saúde, devido à grande quantidade de residentes em áreas rurais, o gestor aponta a pouca informação a respeito das atividades oferecidas para idosos no município. Esses programas foram citados em apenas dois 
grupos focais de forma espontânea, o que pode sinalizar uma baixa valorização deste tipo de ação e a pouca articulação da APS com a Assistência Social.

Por que a gente não tem mais idosos nos programas de promoção da saúde? É realmente a locomoção. Não tem carro, é a distância, não tem ônibus. Alguns são sozinhos, então eles continuam excluídos. Eles querem, mas não tem como vir. Acaba o PSF não funcionando porque a gente não faz prevenção. Faz pronto atendimento, basicamente [...] (Médico, G7).

A queixa de falta de estrutura para o suporte às condiçóes agudas atendidas nas unidades de saúde da família, assim como para o transporte destas urgências para a emergência do hospital municipal, foi apontada como problema em $80 \%$ dos grupos focais. Dada a grande abrangência da ESF do município, as características de distribuição da população e vínculo dos usuários, as USFs eram locais muito procurados no caso de urgências. Esta questáo não foi reconhecida pelo gestor como uma dificuldade da atenção primária após a implantação do Serviço de Atendimento Móvel de Urgência (SAMU) no município.

Eles [a Secretaria Municipal de Saúde] falam que aqui não é pra ter urgência, mas chega. Já tive que atender AVC, infarto, edema agudo e aqui a gente não tem nada [...]. Aqui a ambulância demora pra chegar, tem que pegar a Dutra [...] (Médico, G10).

Segundo dados do SIAB, em 2012 foram registradas 3.531 urgências realizadas pela Atenção Primária do município, o $3^{\circ}$ maior número do Médio Paraíba. De acordo com a mesma fonte de dados, desses, apenas 522 foram encaminhadas a serviços de urgência e emergência, um número baixo quando comparado a outros municípios da Regional de Saúde (DATASUS, 2014b). Isto pode significar que a Atenção Primária acaba por absorver grande parte das pequenas urgências que são resolvidas na própria USF, mesmo considerando as queixas de falta de estrutura mencionadas pelos profissionais de saúde da Saúde da Família.

A dificuldade de atuação com idosos portadores de declínio funcional, ou idosos frágeis, transferiu a esfera do cuidado ao idoso a um contexto negativo da assistência na ESF. Em todos os grupos focais, as discussôes sobre os maus-tratos à pessoa idosa e outros riscos sociossanitários foram levantadas espontaneamente. A referência dada à falta de estrutura familiar como o principal fator deflagrador de maus-tratos, principalmente relacionada ao abandono ao idoso, foi predominante nos discursos. Todavia, foi possível notar um desconhecimento dos profissionais para classificar tais situaçôes como maus-tratos e de como agir diante deste cenário. Motta, Aguiar e Caldas (2011, p. 782) também descreveram a presença da violência intrafamiliar nos 
relatos de profissionais de saúde da família em três municípios do Estado do Rio de Janeiro, descrita como "dificultadora da atenção e impeditiva para a resolutividade das açôes". Os autores identificaram a dificuldade dos profissionais em realizar as determinaçóes presentes no Estatuto do Idoso diante dos casos suspeitos e confirmados de maus-tratos contra idosos (MOTTA; AGUIAR; CALDAS, 2011).

[...] A falta de apoio familiar é o maior problema. Muitas vezes a família não está nem aí [...] (Enfermeiro, G3).

Nas situaçôes de risco sociossanitário, a ação do ACS foi enfatizada como sucesso. Destaca-se, assim, o papel social que os ACSs assumiram no cotidiano de seu trabalho. Existe uma tentativa de suprir a carência do apoio familiar na sua prática de trabalho, tarefa que é naturalizada por esses profissionais, que entendem como sua competência quando a família não pode ou não quer assumir o cuidado.

[...] Tem família que nem pra ir para os exames vai. Aí, o agente tem que ir com ele [o idoso] (ACS, G4).

O vínculo com o idoso, protagonizado pelos ACSs, foi enfatizado em todos os grupos focais e pelo gestor como fator que contribuía para a qualidade da assistência para esse grupo. Na opinião dos profissionais, a construção de relaçóes de confiança e afeto com o idoso permitia a realização de ações mais efetivas nas práticas terapêuticas. De acordo com Merhy (1997), o vínculo pode ser considerado um substrato tecnológico que pode dar o sentido do usuário no interior do processo de trabalho em saúde.

O fortalecimento da APS é visto como ponto-chave para a estruturação de uma RAS (MENDES, 2011), característica que o município estudado alcançou por meio de investimentos na capacitação dos ACSs e da distribuição geográfica das unidades de saúde da família. Para Mendes (2011), a acessibilidade geográfica da APS constitui uma das dimensóes necessárias para o acesso às RASs, devendo ser dispersa territorialmente; ao contrário, os serviços de maior densidade tecnológica, como hospitais, tendem a ser concentrados.

Não há um modelo de atenção ao idoso no município baseado na estratificação de risco e avaliação funcional, como preconizado nas Diretrizes para o cuidado das pessoas idosas no SUS (BRASIL, 2014). Este processo é realizado de maneira praticamente intuitiva pelos ACSs de Piraí, que apontam a maior necessidade de cuidado da equipe àqueles idosos "muito adoecidos" ou "acamados". Assim, o 
planejamento terapêutico fica prejudicado. A não identificação das demandas do usuário idoso dificulta o papel de coordenação do cuidado atribuído à APS (BRASIL, 2014; MORAES, 2012).

O quadro 1 mostra uma síntese das ideias centrais contidas nos relados dos profissionais de saúde e do gestor de saúde sobre a categoria Atenção Primária à Saúde. A categoria inclui os aspectos positivos e negativos apontados sobre o processo de trabalho dos profissionais de saúde na assistência ao idoso. Retrata também, na opinião dos sujeitos, o papel da APS na atenção a esse grupo.

Quadro 1. Categoria Atenção Primária à Saúde: ideias centrais dos relatos dos profissionais de saúde da Atenção Primária e do gestor de saúde. Piraí, 2012.

\begin{tabular}{|l|l|}
\hline Gestor de saúde & Profissionais de saúde \\
\hline Percepçóes Negativas: & Percepçóes Negativas: \\
- Falta de capacitação do médico & - Falta de médicos \\
- Alta rotatividade do médico & - Dificuldade na realização das açôes de \\
- Dificuldade na realizaçáo das açóes de & promoção e prevenção \\
promoção e prevenção & - Maior tempo no atendimento a idosos \\
- Sobrecarga do ACS e enfermeiros & - Dificuldade nos atendimentos às urgências \\
& - Alta demanda para visita domiciliar \\
& - Falta de apoio da família \\
Percepçóes Positivas: & - Sobrecarga de trabalho \\
- Atenção Primária como porta de entrada & - Acesso da populaçáo à ESF \\
- Vínculo do ACS com o idoso & - Vinculo dos ACSs com o idoso \\
- Incentivo à formação técnica de & - Trabalho em equipe \\
enfermagem para os ACSs & \\
\hline
\end{tabular}

\section{Categoria Articulação da APS com outros pontos da atenção}

A APS de Piraí é considerada porta de entrada da população idosa no serviço de saúde do município. É esta a responsável pelo encaminhamento do idoso para os recursos da atenção secundária e terciária, como consultas de especialistas e exames de média e alta complexidade. 
[...] Ela [A Atenção Primária] funciona como porta de entrada. [...] Ele [o idoso] não entra em nenhuma rede especializada sem passar pela atenção primária (Gestor).

Osencaminhamentosa médicosespecialistase exames de médiaealta complexidade feitos pelo Sistema Nacional de Regulação (SISREG) foram considerados problemas na assistência em $80 \%$ das unidades avaliadas. $\mathrm{Na}$ opinião dos profissionais, os idosos frágeis estavam ainda mais sujeitos a encontrar dificuldades para o acesso, uma vez que dependiam da presença de um acompanhante e da liberação do serviço de transporte ao paciente. Assim, a falta do paciente idoso aos procedimentos agendados também foi apontada como problema.

[...] Temos dificuldade no atendimento de "neuro", "oftalmo"... Na verdade, o que a gente não tem demanda reprimida é cardiologia (Enfermeiro, G7).

Um ponto de sucesso relatado foi a criação de uma Central de Exames em uma USF que possui maior número de usuários adscritos. Esta central, responsável pelo agendamento e contato com o usuário, foi descrita como uma estratégia que aumentou o vínculo da unidade com o usuário e diminuiu as faltas nos procedimentos agendados. Além disso, o redimensionamento de vagas de acordo com as demandas das unidades e a contratação de serviços não disponíveis no município foram apresentados pelo gestor como estratégias para superar as dificuldades de acesso.

De acordo com dados do SIAB de 2002 a 2012, junto com a elevação do número de consultas a idosos na Atenção Básica, aumentou também o número de encaminhamentos para atendimento ou tratamento em qualquer especialidade, incluindo as consultas de equipe multidisciplinar. Com relação ao número de ambulatórios da atenção secundária e terciária para suprir esta demanda, houve o incremento no município de dois ambulatórios de atenção secundária, ou média complexidade, passando de 18 a 20 ambulatórios, e a criação de um ambulatório de atenção terciária, ou alta complexidade, no período (DATASUS, 2014a).

$\mathrm{O}$ relato da existência de filas de espera para especialistas e exames também está presente no depoimento do gestor de saúde. Nesse ponto, diferentemente dos profissionais de saúde, o gestor ressalta o encaminhamento desnecessário a especialistas e a falta de informaçôes no SISREG como causa da geração de fila de espera. Contrariando pressupostos (SERRA, 2010), o acesso a serviços hospitalares de internação e procedimentos eletivos hospitalares não foram citados nos grupos focais e na entrevista com o gestor como problemas na assistência. Segundo os dados do 
DATASUS (2014b), das 448 internaçóes de habitantes maiores de 60 anos residentes de Piraí no ano de 2012, 95\% foram realizadas no Hospital Municipal Flávio Leal.

Entretanto, a comunicação entre o hospital e as USFs foi citada como deficiente. Para reduzir este ruído, as USFs realizavam a busca ativa de informaçôes do paciente internado. Esta medida, associada à orientação do familiar pelo ACS e à marcação de visita domiciliar logo após a alta, foi citada como responsável pela melhora na troca de informaçóes entre os serviços e melhor continuidade do cuidado.

A falta de rede de suporte social, caracterizada principalmente pela carência de apoio da família no cuidado ao idoso e potencializada pela baixa escolaridade e renda da populaçáo local, prejudicava diversas etapas da assistência. $\mathrm{O}$ baixo número de unidades de proteção social e o recurso financeiro limitado da Secretaria Municipal de Assistência Social também foram citados como limitadores da assistência na APS pelo gestor. Este fator é complicado pelo menor valor social do idoso e acaba por fomentar a vulnerabilidade dessa população diante das dificuldades encontradas na comunidade. Durante as entrevistas, pôde-se perceber que a velhice foi associada à perda da capacidade produtiva, à dependência e à inutilidade do ponto de vista social.

[...] Só tem um asilo em Pinheiral [município vizinho], mas fica longe pra quem mora aqui. Como vão visitar ele lá? Aí nenhum idoso quer ir pra lá (ACS, G6).

[...] Eu acho que a Assistência Social [SMAS] tinha que ser alguma coisa do porte da Saúde [SMS]. Mas não é e está longe de ser [...]. Então tem que se começar a pensar políticas públicas para essa população de sozinhos [...] (Gestor de saúde).

Os modelos de atenção a idosos incluem os recursos de assistência domiciliar, ambulatórios especializados, centros-dia, hospital de procedimentos, ILPI e instituiçôes de cuidados paliativos de acordo com as necessidades identificadas a partir da avaliaçấo multidimensional do idoso (VERAS, 2012). Ou seja, existe uma íntima comunicação entre os recursos oferecidos da Saúde e da Assistência Social.

Os obstáculos identificados no cuidado do idoso frágil, além de permeados pelo desconhecimento, foram exacerbados pela falta de apoio das estruturas dos níveis de atenção. A tentativa da APS em absorver todo o cuidado do idoso frágil resultou em problemas na atenção a este grupo e na sobrecarga dos profissionais de saúde da ESF. Há necessidade, portanto, de se reconhecer os limites da APS no seu papel de acompanhamento a idosos frágeis. É preconizado que o acompanhamento desse grupo de idosos seja apoiado por serviços especializados em geriatria (MORAES, 2012). 
Seja na violência intrafamiliar quanto na violência institucional, a dicotomia dos setores da Saúde com a Assistência Social do município se torna um obstáculo para o enfrentamento destas questóes, que requerem informação, trabalho em equipe, capacitação profissional e a integração dos diversos setores.

Apesar dos esforços pontuais de se tentar superar os problemas da articulação entre a atenção primária e outros níveis de atenção, o sistema de saúde do município ainda depende de uma linha frágil de comunicação entre estes pontos. Na opiniáo dos sujeitos, grande desenvolvimento da atenção primária e menor aprimoramento dos níveis de atenção secundário e terciário associados ao pouco investimento de açôes intersetoriais de tecnologia de informação, transporte, urbanismo e de assistência social repercutiram na falta de continuidade da assistência. A fragmentação do cuidado é apontada por estudos internacionais como responsável por uma resposta muitas vezes insuficiente das demandas do usuário, propiciando a perda de capacidade funcional do idoso e levando a um consequente aumento dos gastos com o sistema de saúde (VERAS et al., 2014).

A tentativa de se trabalhar em "rede" com a implantação de procedimentos burocráticos e normativos para encaminhamento aos serviços de atenção secundária e terciária acabou por enrijecer o sistema de atenção do município, diminuindo o acesso da população a estes serviços. Como apontado por Quinderé et al. (2014), o ato do cuidado pode romper a norma estabelecida e construir novos fluxos de forma $\mathrm{a}$ atender $\mathrm{o}$ usuário.

O quadro 2 apresenta os principais pontos levantados sobre a categoria Articulação da APS com outros pontos da atenção: níveis de atenção secundário e terciário, intersetorialidade e aspectos sobre a integração dos serviços. 
Quadro 2. Categoria Articulação da APS com outros pontos da atenção: níveis de atenção secundário e terciário, intersetorialidade e aspectos sobre a integração dos serviços. Piraí, 2012.

\begin{tabular}{|l|l|}
\hline Gestor de saúde & Profissionais de saúde \\
\hline Percepçóes Negativas: & Percepçóes Negativas: \\
- Fila de espera para especialistas & - Fila de espera para especialistas \\
- Mau preenchimento do encaminhamento & - Falta dos usuários às consultas agendadas \\
pelo médico & - Dificuldade de comunicação entre os níveis \\
- Encaminhamento desnecessário a & de atençáo \\
especialistas pela AB & - Falta de resposta da Assistência Social \\
- Falta de unidades de apoio de proteção & \\
social ao idoso & \\
- Falta de recursos financeiros da Assistência & \\
Social & \\
Percepçóes Positivas: & \\
- Contrataçáo de serviços fora do município & - Serviço da Central de Exames nas USFs \\
pela SMS & - Busca ativa de informaçóes sobre pacientes \\
- Redimensionamento de vagas no SISREG & internados \\
de acordo com as demandas nas USFs & \\
\hline
\end{tabular}

\section{Considerações finais}

A análise do processo da assistência ao idoso na APS e da estrutura operacional que o município dispôe para seu acompanhamento contrasta com as experiências internacionais reconhecidas como de êxito na assistência integral ao idoso e com as diretrizes nacionais para cuidado das pessoas idosas no SUS. Trata-se de um sistema fragmentado de saúde. A rede de atenção, da forma como descrita, não existe no município. Entretanto, é inegável que a ampla abrangência da APS de Piraí e o maior vínculo do idoso com a equipe da ESF são passos importantes alcançados no município na busca da melhor qualidade da assistência a sua população. Estas características são pontos básicos para se pensar futuras intervençôes visando à estruturação de uma rede de atenção ao idoso.

A pessoa idosa possui demandas e particularidades biopsicossociais que a diferenciam de um usuário adulto. Nesse sentido, destaca-se a importância de 
se romper com a ideia de um modelo único para atendimento à população, que limita a assistência de acordo com as necessidades do sistema e não do usuário. Há necessidade, portanto, da elaboração de modelos de atenção a idosos que guiem o fluxo desses usuários no sistema de saúde, mas que, ao mesmo tempo, permitam a flexibilização e organização das açóes de cuidado a partir das demandas dos pacientes. Muitos passos são ainda necessários para se alcançar um sistema de saúde "sem muros", eliminando as barreiras de acesso entre os diversos níveis de atenção, com vistas à otimização de recursos e ampliação das oportunidades de cuidados adequados para esta população atualmente excluída.

As percepçóes dos profissionais de saúde e gestor sobre a assistência ao idoso emergiram fortemente marcadas pela desvalorização social da velhice. As visões dos sujeitos foram carregadas de desconhecimento acerca dos temas de geriatria e gerontologia e acompanhadas de uma naturalização da perda de independência do idoso. Ressalta-se a importância da ressignificação do envelhecimento no seu contexto social com a compreensão da importância do papel do idoso na sociedade e da necessidade de se garantir os meios necessários para que ele seja capaz de exercer a sua cidadania.

Apesar de ter alcançado os objetivos propostos, é importante salientar que este estudo teve como limitação o fato de focar nas percepçôes dos profissionais de saúde e dos gestores, não agregando o olhar do usuário idoso. Sendo esta a proposta de estudos futuros para o município de Piraí. Há que se considerar que a metodologia proposta impossibilita a generalização dos resultados. Espera-se que os conhecimentos gerados possam se transformar em subsídios para a implementação de um modelo de atenção à saúde do idoso adequado à realidade local. ${ }^{1}$

\section{Agradecimentos}

Agradecemos à Secretaria Municipal de Saúde de Piraí, pelo aceite e pelas contribuições na realização da pesquisa.

\section{Referências}

BRASIL. Ministério da Saúde. Diretrizes para o cuidado das pessoas idosas no SUS: proposta de modelo de atenção integral. XXX Congresso Nacional de Secretarias Municipais e Saúde. Brasília: Ministério da Saúde, 2014. 41 p. 
. Portaria $n^{\circ}$ 2528, de 20 de outubro de 2006. Aprova a Política Nacional de Saúde da Pessoa Idosa. Brasília: Diário Oficial [da] República Federativa do Brasil, 2006.

. Portaria $n^{\circ} 4279$, de 30 de dezembro de 2010. Estabelece diretrizes para a organizaçáo da Rede de Atenção à Saúde no âmbito do Sistema Único de Saúde (SUS). Brasília: Ministério da Saúde, 2010. 88.

- Saúde da Família: uma estratégia de organização dos serviços de saúde. Brasília: Ministério da Saúde, 1996.

- Secretaria de Atenção à Saúde. Departamento de Atenção Básica. Política Nacional de Atenção Básica. 4. ed. Brasília: Ministério da Saúde, 2007. 68 p.

DEPARTAMENTO DE INFORMÁTICA DO SUS (DATASUS). Base de dados na Internet. Cadastro Nacional de Estabelecimentos de Saúde (CNES). Disponível em: <http://datasus.saude. gov.br/sistemas-e-aplicativos/cadastros-nacionais/cnes>. Acesso em: out. 2014a.

. Base de dados na Internet. Sistema de Informação da Atenção Básica (SIAB). Disponível em: <http://www2.datasus.gov.br/SIAB/index.php>. Acesso em: out. $2014 \mathrm{~b}$.

. Base de dados na Internet. Informaçóes de saúde (TABNET). Disponível em: <http:// www2.datasus.gov.br/DATASUS/index.php?area=0205>. Acesso em: out. 2014c.

GIOVANELlA, L.; MENDONÇA, M.; ALMEIDA, P. et al. Saúde da família: limites e possibilidades para uma abordagem integral de atenção primária à saúde no Brasil. Ciênc. Saúde Coletiva. Rio de Janeiro, v. 14, n. 3, p. 783-94, 2009.

MARTINS, A.; D’AVIlA, O.; HILGERT, J. et al. Atenção Primária à Saúde voltada às necessidades dos idosos: da teoria à prática. Ciênc. Saúde Coletiva. Rio de Janeiro, v. 19, n. 8, p. 3403-3416, 2014.

MENDES, E. As redes de Atenção à Saúde. Ciênc. Saúde Coletiva. Rio de Janeiro, v. 15, n. 5 , p. 2.297-305, 2010.

MERHY, E. E.; ONOCKO, R. (Orgs.). Agir em saúde: um desafio para o público. São Paulo: Hucitec, 1997, p. 71-112.

MINAYO, M. O desafio do conhecimento: pesquisa qualitativa em saúde. 13. ed. Sáo Paulo: Hucitec, 2013.

MORAES, E. Atenção à saúde do idoso: aspectos conceituais. Brasília: Organização PanAmericana da Saúde, 2012.

MOTTA, L.; AGUIAR, A. Novas competências profissionais em saúde e o envelhecimento populacional brasileiro: integralidade, interdisciplinaridade e intersetorialidade. Ciênc. Saúde Coletiva. Rio de Janeiro, v. 12, n. 2, p. 363-372, 2007.

MOTTA, L.; AGUIAR, A.; CALDAS, C.P. Estratégia Saúde da Família e a atenção ao idoso: 
experiências em três municípios brasileiros. Cad. Saúde Pública. Rio de Janeiro, v. 27, n. 4, p. 779-786, Abr. 2011.

QUINDERÉ, P.; JORGE, M. S.; FRANCO, T. Rede de Atenção Psicossocial: qual o lugar da saúde mental? Physis: Revista de Saúde Coletiva. Rio de Janeiro, v. 24, n. 1, p. 253-271, 2014. SERRA, C.; RODRIGUES, P. Avaliação da referência e contrarreferência no Programa Saúde da Família na Região Metropolitana do Rio de Janeiro (RJ, Brasil). Ciênc. Saúde Coletiva. Rio de Janeiro, v. 15, n. 3, p. 3.579-3.586, 2010.

VERAS, R. Envelhecimento populacional contemporâneo: demandas, desafios e inovaçôes. Rev Saúde Pública. Rio de Janeiro, v. 43, n. 3, p. 548-554, 2009.

. Prevenção de doenças em idosos: os equívocos dos atuais modelos. Cad. Saúde Pública, Rio de Janeiro, v. 28, n. 10, p. 1834-1840, 2012.

VERAS, R.; CALDAS, C.; MOTTA, L. et al. Integração e continuidade do cuidado em modelos de rede de atenção à saúde para idosos frágeis. Rev Saúde Pública. Rio de Janeiro, v. 48, n. 2, p. 357-65, 2014.

\section{Nota}

${ }^{1}$ L. P. Coelho realizou a coleta, análise e interpretação dos dados e revisão do artigo. L. B. da Motta e C. P. Caldas contribuíram para a concepção do projeto, análise dos dados e revisão do artigo. 


\section{Abstract}

\section{Elderly care network: facilitating factors and barriers to implementation}

This article aimed to identify and discuss the factors that favor and hinder the implementation of an Integrated Delivery Network Service for the Elderly in a municipality with $100 \%$ coverage by the Family Health Strategy. Using a qualitative method, ten focus groups were conducted, a semi-structured interview with the municipal health manager was performed, and the results were compare with the structure of the local health system. The results revealed that the current logic of the work process in primary health care does not differentiate the care delivered to the elderly from the one provided to adults. Despite the consolidation of primary health care as an entry point and the strong presence of community health agents in the studied city, fragmentation of the health system and the absence of a model of health care for the elderly are still limiting factors for comprehensive care. Lack of human resources training and devaluation of old age aggravate this scenario. It is expected that the knowledge generated by this study can be turned into subsidies for the implementation of a model for elderly care suitable to local conditions.

> Keywords: elderly's health; elderly's healthcare; primary healthcare; Family Health Strategy. 